\title{
MODIFIED DOUGHNUT TECHNIQUE IN REDUCTION MAMMOPLASTY FOR BREAST CANCER
}

\author{
Samy A. Abdl Rhaman, Sherif Mourad, Hossam El Sadek, and \\ Hoda E. Gerges
}

Department of General Surgery, Faculty of medicine, Ain Shams University. Cairo, Egypt

\section{Corresponding:}

Hoda Ezzat Gerges

Mobile : 01221096023

E mail:

Email:

hoda_ezzat@hotmail.com

Received: 29/1/2020

Accepted: 27/2/2020

Online ISSN: 2735-3540

\begin{abstract}
:
Background: Breast cancer is the commonest malignancy in women and comprises $18 \%$ of all female cancers. The goal of modern breast surgery is to cure patients with preservation and reconstruction of breast tissue leading to satisfactory physical and psychological outcome.
\end{abstract}

Aim of the Work: to evaluate modification of Dougnut technique in reduction mamoplasty as part of oncoplastic breast surgery for breast cancer.

Patients and Methods: This prospective study included 20 female patients diagnosed with breast cancer suitable for management with the modified doughnut breast oncoplastic reduction mammoplasty surgery the age of the patients varied from 22 and 60 years old. The mean age for our study was 46.5.

Results: From the 20 patients, the most common were of cup size $C$ and $D$ with the later being the mean and accounting for more than half (55\%). The mean tumor size was $3.37 \pm 1.01$ with a mean distance from NAC of $2.86 \pm 0.85$. The location was $60 \%$ paraaereolar and $40 \%$ in the lower half of the breast. 13 (65\%) patients underwent operation unilateral and 7 (35\%) patients underwent bilaterally. The most common tumor pathology was IDC (70\%). Regarding our patients' cosmetic satisfaction, the overall mean score of our study was 4.35 which falls between very good and excellent

Conclusion: The modification of oncoplastic surgical techniques allows combining of several benefits, as here the modified doughnut technique benefiting from combining the round block and superior medial techniques giving better access of tumors and oncological control around the breast and reduction mammoplasty in large breast of cup C, D and more, with safe NAC and good aesthetic outcome. That technique showed good adoption bilaterally which is a key for symmetrization in oncoplastic surgeries.

Key words: modified Doughnut technique, reduction mammoplasty, breast cancer

\section{INTRODUCTION:}

The purpose of oncoplastic surgery for breast cancer is to improve the cosmetic outcome without impacting local control after resection $^{(\mathbf{1})}$.
Recently, advances in oncoplastic techniques are capable of preserving the breast form and quality of life. Among technical options, therapeutic reduction mammaplasty remains a useful procedure since the breast-conservation surgery defect 
can be repaired and the preoperative appearance can be improved. Additionally, it permits wider excision of the tumor, with a superior mean volume of the specimen and potentially reduces the incidence of margin involvement. The main advantages of the technique utilized should include reproducibility, low interference with the oncological treatment and long-term results. The success of the procedure depends on patient selection, coordinated planning and careful intra-operative management ${ }^{(\mathbf{1})}$.

In the past, macromastia has been considered a contraindication for BCT owing to difficulties in administering radiation therapy at the surgical site so it has become standard procedure for a select group of patients with both breast cancer and breast hypertrophy.

So although numerous methods over the years have been designed to reduce their size and weight, but volume reduction alone is not enough. The goal today is to not only reduce size but also create a pleasing shape and, if possible, preserve sensation and function using a skin incision pattern best suited to the individual patient ${ }^{(2)}$.

\section{AIM OF THE WORK:}

To evaluate modification of Dougnut technique in reduction mamoplasty as part of oncoplastic breast surgery for breast cancer.

\section{PATIENTS AND METHODS:}

This was a prospective study that included 20 patients with stage primary breast malignancy stage I and II .

Oncoplastic procedures were proposed for patients in whom they have large breast size of cup $\mathrm{C}$ and more and where breast conservative treatment is possible on oncologic grounds but a standard resection without oncoplasty would lead to a poor aesthetic outcome. Diagnosis and staging examinations were carried out according to the standard protocol being conducted at Ain Shams University Hospitals.

Excision of the tumor with a wide clear safety margins down to the pectoral fascia with frozen section confirmation performed for all patients, along with axillary lymph node dissection according to our standard protocol.

Immediate reconstruction and reduction mammoplasty of the breast was carried out using the modified doughnut technique.

In-patient post-operative recovery time ranged from one to two days according to patient response. All patients were discharged with a set of instruction and follow up schedule.

Our patients were all followed up for both oncologic and cosmetic grading and were referred to receive suitable adjuvant chemo and or radiotherapy according to the final pathology reported after conventional pathological evaluation.

Patient selection was achieved through a number of inclusion and exclusion criteria

The study included female patients ranging from the age of 20 to 60, Patient's breast size cup $\mathrm{C}$ or more, tumors that are located in lower half of breast or paraareolar, imaging studies confirming pathoanatomic features corresponding to clinical symptoms and patients with histopathological diagnosis confirming the clinical features and manifestations. A patients were well-informed and well consented.

While female patients below the age of 20 or above the age of 60 , Tumors that are multicentric in more than 3 quadrants, Central or retroarelar tumors, Inflammatory breast cancer or (externsice DCIS componenet of more than 25\%), patients with multiple co morbidities, Patients who underwent any previous breast surgeries, Patients that are pregnant or lactating, Patients with absolute contraindication for 
oncoplasty, Non-compliant patients which are patients demanding mastectomy for fear of local recurrence, patients not convinced with proposed procedure after adequate explanation and patients refusing postoperative adjuvant radiotherapy were excluded from the study.

\section{All patients were submitted to the following:}

History taking and Clinical examination in the outpatient clinic Pre-operative investigation performed that included: Laboratory tests: Radiological examination: including bilateral digital mammography ,MRI of the breast in a few selected cases as indicated and chest X-ray, abdominal and pelvic ultrasound as part of our metastatic work up protocol, bone scan as indicated and upon the patients complaint from bony ache. Tissue biopsy using true cut needle core biopsy in all patients was indicated Multidisciplinary team Multi-disciplinary team at the breast unit at General Surgery Department of Ain Shams University Hospital reviewed every single case independently. The MDT Included: Breast surgery consultant, Pathology consultant, Radiology consultant. Oncology consulatant Discussion was made up upon every case, including her history, examination and investigations. A formal consent was written and explained to the patient. The consent was signed one day prior to surgery and any inquiries, concerns or doubts were discussed with the patient and a first degree relative (upon the patient's request).

\section{Medical photography:}

The need for medical photography was also discussed and explained. Medical photos were taken and kept in the patient's records as agreed upon.

\section{Mark up prior surgery:}

Mark up and design of planned incision were done while the patient standing up on the morning of the surgery in the holding area of the operating theatre in the presence of the breast nurse and the surgical team.

\section{Technique:}

The preoperative drawing is done with the patient standing up, two concentric circle were drown, inner circle is at the circumareolar margin, outer circle is planned according to patient breast size ranging from $1-2 \mathrm{~cm}$ on each side reaching a maximum diameter $4 \mathrm{~cm}$ more than inner circle. Injection of saline-adernaline sub dermal was done deepithelization were done between the two circles.

\section{Post-operative management:}

Prophylactic broad spectrum antibiotics were administrated to all patients upon induction and during the whole period of hospital stay.

Post-operative strong analgesia in the form of pethedine $50 \mathrm{mg}$ after recovery from anesthesia followed by NSAIDs fixed dose every 8 hours in the first 24 hours.

Patients were discharged at the second day post-operative if everything is fine. Patients were discharged on antibiotics, analgesics and anti-edema agents. They were advised to wear well-fitting sports bra following all reconstruction procedures.

Drains were removed in follow up visits when daily volume is less than $40-50 \mathrm{ml}$.

\section{Follow up:}

Patients were given a follow up schedule upon discharge from the hospital as the following: First week every three days for dressing and monitoring the drains. The following two weeks every four to five days until removal of the drains and stitches.

\section{Assessment of cosmetic outcome:}

Cosmetic outcome was evaluated during the early post-operative period and on follow up. Evaluation was done by means of scoring system, graded from one to five, one 
indicating poor results and five indicating excellent results.

Pictures were taken before and after surgery for comparison in terms of breast contour, breast size and shape, degree of ptosis, NAC deviation and degree of asymmetry.

Cosmetic outcome was evaluated through a scoring system, graded from one to five, one indicating poor results and five indicating excellent results. It was evaluated by the breast MDT and the BREAST-Q questionnaire filled by the patient.

\section{RESULTS:}

The age of the patients varied from 22 and 60 years old. The mean age for our study was 46.5 (Table 1).

Table (1): Mean age of the study

\begin{tabular}{|l|c|}
\hline \multicolumn{1}{|c|}{ Age (years) } & Total no. $=20$ \\
\hline Mean \pm SD & $46.5 \pm 8.41$ \\
\hline Range $(22-60)$ & $\%$ \\
\hline$(20-40)$ & $2(10 \%)$ \\
\hline$(30-40)$ & $1(5 \%)$ \\
\hline$(40-50)$ & $9(45 \%)$ \\
\hline$(50-60)$ & $8(40.0 \%)$ \\
\hline
\end{tabular}

\section{1- Breast cup size}

The breast cub size was estimated for every single case and a score was given for each cup size as the following: (Table 2)

Table (2): Breast cup size score given for the cases in the study.

\begin{tabular}{|l|c|}
\hline \multicolumn{1}{|c|}{ Breast cup size } & Given score \\
\hline Breast Cup Size C & 1 \\
\hline Breast Cup Size D & 2 \\
\hline Breast Cup Size E & 3 \\
\hline Breast Cup Size F & 4 \\
\hline
\end{tabular}

Table (3): Number of patients with different cup sizes and the mean cup size.

\begin{tabular}{|l|l|c|}
\hline \multicolumn{2}{|c|}{} & Total no. $=\mathbf{2 0}$ \\
\hline \multirow{4}{*}{ Breast cup size } & C & $5(25.0 \%)$ \\
\cline { 2 - 3 } & D & $11(55.0 \%)$ \\
\cline { 2 - 3 } & E & $3(15.0 \%)$ \\
\cline { 2 - 3 } & F & $1(5.0 \%)$ \\
\hline \multirow{2}{*}{$\begin{array}{l}\text { Breast cup } \\
\text { score }\end{array}$} & Mean \pm SD & $2 \pm 0.79$ \\
\cline { 2 - 3 } & Range & $1-4$ \\
\hline
\end{tabular}

The mean breast cup size for the whole study was 2 which stand for D (Table 3)

The minimum breast cup size was $\mathbf{C}$,

The maximum was $\mathbf{F}$.

\section{Tumor}

\section{1- Tumor size}

The tumor size was evaluated by ultrasound done for all cases before operation as an integral step of the triple assessment. The tumor size is evaluated along the longest diameter of the tumor mass. The smallest tumor size was $1.4 \mathrm{~cm}$, the largest one was $5 \mathrm{cmcms}$ and the mean tumor size was $3.4 \mathrm{cms}$ (Table 4).

The distance from the nipple areola complex was variable among the cases of the study, the nearest tumor was $1.7 \mathrm{~cm}$ from $\mathrm{NAC}$, and the farthest was $5.2 \mathrm{cms}$ from NAC. With mean distance $2.84 \mathrm{cms}$.

Table (4): Mean tumor size, distance and location from NAC

\begin{tabular}{|l|c|c|}
\hline \multicolumn{2}{|c|}{} & Total no. $=20$ \\
\hline \multirow{2}{*}{ Tumor size $(\mathrm{cm})$} & Range & $1.4-5$ \\
\cline { 2 - 3 } & Mean \pm SD & $3.37 \pm 1.01$ \\
\hline \multirow{2}{*}{ Distance from NAC } & Range & $1.7-5.2$ \\
\cline { 2 - 3 } & Mean \pm SD & $2.86 \pm 0.85$ \\
\hline Location & Paraareolar & $12(60.0 \%)$ \\
\cline { 2 - 3 } & Lower half & $8(40.0 \%)$ \\
\hline
\end{tabular}

8 of the cases the tumor was paraareolar $40 \%$, and 12 of the cases the tumor was in the lower half of the breast $60 \%$.

\section{Unilateral or bilateral cases operated upon:}

In our study 7 patients agreed for bilateral breast operation, on the tumor side and contralteral breast reduction symmertization and 13 cases for unilateral breast operation only on the tumor side.

Table (5): Percentage of breast side operated upon

\begin{tabular}{|c|l|c|}
\hline \multicolumn{2}{|c|}{} & Total no. $=20$ \\
\hline \multirow{2}{*}{ Bilateral or unilateral } & UNI & $13(65.0 \%)$ \\
\cline { 2 - 3 } & BI & $7(35.0 \%)$ \\
\hline
\end{tabular}


The bilateral 7 cases are $35 \%$ and the 13 cases unilateral $65 \%$.

\section{Operative evaluation:}

\section{1- Operation time and postoperative stay:}

Our mean operation time for the unilateral cases was 136 minutes ( 2 hour and 26 minutes), the fastest procedure finished in 120 minutes, longest took 195 minutes.

For bilateral cases the contra lateral breast needed an added 75 to 90 minutes

Table (6): Mean operation time for our study

\begin{tabular}{|l|l|c|}
\hline \multicolumn{2}{|c|}{} & Total no. $=20$ \\
\hline Unilateral operative time (min) & Mean \pm SD & $136.25 \pm 15.2$ \\
\cline { 2 - 3 } & Range & $120-195$ \\
\hline Contra lateral operative time (min) & Mean \pm SD & $81.71 \pm 5.41$ \\
\cline { 2 - 3 } & Range & $75-90$ \\
\hline Total operative time (min) & Mean \pm SD & $164.85 \pm 48.05$ \\
\cline { 2 - 3 } & Range & $120-274$ \\
\hline Postoperative hospital stay (hours) & Mean \pm SD & $30 \pm 12$ \\
\cline { 2 - 3 } & Range & $24-72$ \\
\hline
\end{tabular}

\section{Comorbidities and post-operative complications:}

On pre-operative patient preparation, 4 patients among the 20 patients were found to have medical comorbidities. 2 patient have hypertension, 1 patients have hypertension and diabetes mellitus, and 1 patient have ischemic heart disease (Table 7).

Patients were given a follow up schedule upon discharge from the hospital as the following in the form of 3 visits in the first week for dressing and monitoring the drains and any complications case of nipple necrosis. dressings were needed with a mean time of 82 minutes.

Making the mean time for bilateral cases 164 minutes of 2 hours and 73 minutes.

Most of the patients were discharged at the morning of the second day postoperative (i.e. 24 hours post-operative).

The mean post-operative stay period 30 hours, however the longest post-operative stay period was 3 days (Table 6).

During the follow up period complications occurred only in 3 cases, in the form of: 2 cases of infection and one

It worth noting that the 2 patients who have had wound infection one of them was diabetic, this reflects the effect of DM on immune system compromisation. The 2 patients were managed with antibiotics and

And in our study one patient only had nipple necrosis, and it's worth mentioning that she was the patient with both DM and hypertension.

Table (7): Comorbidities and post-operative complications among patient population.

\begin{tabular}{|c|c|c|}
\hline & & No. and $(\%)$ \\
\hline \multirow[t]{2}{*}{ Morbidity } & No & $16 \ldots \ldots \ldots \ldots(80.0 \%)$ \\
\hline & Yes & $4 \ldots \ldots \ldots \ldots(20.0 \%)$ \\
\hline \multirow[t]{3}{*}{ Type of morbidity } & DM & $1 \ldots \ldots \ldots \ldots(5.0 \%)$ \\
\hline & HTN & $3 \ldots \ldots \ldots \ldots(15.0 \%)$ \\
\hline & IHD & $1 \ldots \ldots \ldots \ldots(5.0 \%)$ \\
\hline \multicolumn{2}{|c|}{ Postoperative Complications } & No. \& $(\%)$ \\
\hline \multicolumn{2}{|l|}{ No } & $\ldots \ldots \ldots \ldots(85.0 \%)$ \\
\hline \multicolumn{2}{|l|}{ Yes } & $3 \ldots \ldots \ldots \ldots \ldots \ldots \ldots \ldots \ldots \ldots \ldots \ldots \ldots,(15.0 \%)$ \\
\hline \multicolumn{2}{|l|}{ Infection } & $\ldots \ldots \ldots \ldots \ldots(10.0 \%)$ \\
\hline \multicolumn{2}{|l|}{ Nipple necrosis } & f.................. (5.0\%) \\
\hline
\end{tabular}




\section{Post-operative pathological outcome:}

Post-operative results provided by our pathologist showed that 14 of our patients had (IDC), 3of our patients had (ILC) and 1 of them had mixed IDC and ILC carcinoma and 2 of them had mixed IDC and DCIS.

Table (8): Postoperative percentage of postoperative pathological type of tumor.

\begin{tabular}{|c|c|}
\hline Postoperative pathological outcome & No. (\%) \\
\hline IDC & $14(70.0 \%)$ \\
\hline ILC & $3(15.0 \%)$ \\
\hline Mixed IDC \& ILC carcinoma & $1(5.0 \%)$ \\
\hline Mixed IDC \& DCIS & $2(10.0 \%)$ \\
\hline
\end{tabular}

As regard to oncological safety all of our patients had clear margins in frozen sections taken during the operations and postoperative paraffin section results provided by our pathologist and none of them had recurrence during postoperative follow up period of six months duration or needed further surgery.

\section{Cosmetic outcome:}

Cosmetic outcome was estimated using a scoring system which was made up from the three independent grading parties (Surgeon, Patient and MDT of the breast) by post-operative photographs, then 2 weeks and 1 month on follow up. Evaluation was done by means of scoring system, graded from one to five, one indicating poor results and five indicating excellent results.

The cosmetic outcome score was made up through a check list to be evaluated by the grading parties for every single case, this check list consists of: the overall shape of the breast, the symmetry of both breasts, the site and direction of the nipple, the volume of the breast and the skin incision shape.

These elements were discussed for every single case and analyzed to give a scoring system graded from 1 to 5 as the following:
Table (9):Postoperative cosmetic scoring system.

\begin{tabular}{|c|c|}
\hline Grade & Score \\
\hline Excellent & 5 \\
\hline Very good & 4 \\
\hline Good & 3 \\
\hline Fair & 2 \\
\hline Poor & 1 \\
\hline Ugly & 0 \\
\hline
\end{tabular}

The following is the number of cases for each Grade of the scoring system for the whole study.

Table (10): The mean of cosmetic the outcome for our study.

\begin{tabular}{|c|c|}
\hline Cosmetic outcome & Total no. $=20$ \\
\hline Mean \pm SD & $4.35 \pm 0.875$ \\
\hline Range & $2-5$ \\
\hline
\end{tabular}

The overall mean score of our study was 4.35 which falls between very good and excellent (Table 10).

Table (11): Number of cases of the cosmetic outcome for our study.

\begin{tabular}{|c|c|c|c|}
\hline Grade & Score & Total no. $=20$ & $\%$ \\
\hline Excellent & 5 & 11 & $(55.0 \%)$ \\
\hline Very good & 4 & 6 & $(30.0 \%)$ \\
\hline Good & 3 & 2 & $(10.0 \%)$ \\
\hline Fair & 2 & 1 & $(5.0 \%)$ \\
\hline Poor & 1 & 0 & $(0.0 \%)$ \\
\hline Ugly & 0 & 0 & $(0.0 \%)$ \\
\hline
\end{tabular}

The number of cases given excellent score (Score 5) was 11, the number of cases given very good score (Score 4) was 6, the number of cases given good score (Score 3 ) was 2, the number of cases given fair score (Score 2) was 1, the number of cases given poor score (Score 1) was 0 and the number of cases given ugly score (Score 0 ) was 0 .

Contralateral breast mammoplasty and symmetrization was done in the same setting.

\section{DISCUSSION:}

Worldwide, breast cancer is the most common cancer in women, accounting for $25 \%$ of all cases. Outcomes for breast cancer vary depending mainly on the cancer type, 
extent of disease, and person's age. Survival rates in developed countries can be high reaching to $80 \%$ for at least five years ${ }^{(3)}$.

The oncoplastic breast surgery is based on three basic principles: ideal breast cancer surgery with wider excisions, immediate breast reconstruction, and immediate symmetry of the other breast whenever necessary ${ }^{(4)}$.

They often involve breast reduction or mastopexy reconstructive techniques to facilitate resection of large breast volumes on the side of the breast cancer and accompanied with symmetry contralateral breast reductions or mastopexies ${ }^{(5)}$, hence in our study we made large breast size as an one of the inclusion criteria resulting in the average cup size the patients breasts of cup C \& D.

In our study mean age was 46 with $50 \%$ cases falling between 42 and 58 years which is coinciding with the demographic results of Zeeneldin et al. ${ }^{(6)}$ at National Cancer Institute published that the peak incidence of breast cancer is between $40-59$ years old.

For tumor size, it was between $\mathrm{t} 1$ and $\mathrm{t} 2$ with the mean size of $3.4 \mathrm{~cm}$ and we found the pathological type of breast cancer with the highest prevalence in our study to be of IDC $70 \%$, these were coinciding with A Systematic Literature Review of 474 articles from 55 studies evaluating 6011 patients was T1 (43.8 \%) and T2 (39.3\%) and invasive ductal carcinoma were the most common tumor histopathologies ${ }^{(7)}$.

In another study conducted in rome, Italy 2019 analyzing oncoplastic breast surgeries done over 20 years on 381 women the IDC was the commnest, however it was lower than that of our study as it was $54 \%{ }^{(8)}$.

The reduction of the normal contralateral breast in parallel with the oncoplastic reduction and reconstruction results in smaller-sized breasts that are aesthetically more pleasing, have better symmetry and provide relief from back and neck pain for patients with large, heavy and pendulous breasts ${ }^{(9)}$.

The most appropriate approach in women with Brassiere cup size $\mathrm{C}, \mathrm{D}$ or larger with coexisting ptosis, is a bilateral reduction technique. This approach provides the most desired oncological outcome with attention to the cosmetic result. Additionally, it results in a higher patient satisfaction rate due to their perception of improved aesthetic outcomes. Paridon et al. (10) published the cosmetic outcomes of oncoplastic breast reduction assessed through BREAST-Q surveys that were anonymously completed by the patients, they were satisfied with their breasts at (72.6 $\% \pm 20.4)$ and also satisfied with their outcome (74.6\% $\% 17.6)$. (2017).

That was agreeing with results from our study were More than half of our patients $65 \%$ opted first for unilateral technique, however by the end of the study, half of these patients undergoing unilateral reduction oncoplasty came back asking for the summarization, thus encouraging the point, that the bilteralty in breast reduction techniques is more preferable even in presence of tumors, however that differed from a study in Sweden in 2019 where Most patients in the cohort study, who had undergone breast-conserving therapy with oncoplastic volume displacement techniques, were satisfied with their breasts without surgery to the contralateral breast ${ }^{(11)}$.

A retrospective study was performed in 2097 female patients, undergoing breast reduction and mastopexy, operated on by the senior author with a single central block technique (a superior vascular flap), from July 1985 to December 2018, where it concluded that single central block technique create a new breast with a beautiful breast cone, adequate in volume and shape, with a well-positioned NAC and its vascularization and sensitivity maintained (12), and that was found similar to the reduction part of the technique in our study, 
however added upon it, is the oncological benefit of tumor resection.

Another study that was conducted in UK in 2016 showed that the most common pedicle used in a cohort study was superomedial followed by inferior pedicle, and that technique has a similar bases to our technique in the form of the blood supply to the NAC and the reduction mammoplasty ${ }^{(13)}$.

On the a different note, another study that was conducted in Alexandria, Egypt in 2019 where it was about modified round block technique from the aspect of using it to locate tumors in the peripheries in breast which is claimed as a limitation met in the conventional round block so, the dermis is cut only on the side where the tumor is located as the NAC is supplied from all sides by dermal vessels ${ }^{(14)}$ and that study is agreeing with the doughnut part of our technique that we are using it to locate the tumors around the breast and then adding to it the benefit of reduction form the superior medial pedicle.

Mean operative time for our technique for the unilateral cases was 130 mintues and for the bilateral cases was 212 mintues, and as the study progressed the time improved reaching 120 mintues for uniletral cases and 195 mintues for bilateral cases. This is in comparison to the average of (120 minutes) by Blondeel et al. ${ }^{(15)}$.

Annual recurrence curves indicated that the relapse peak after mastectomy emerged in the first two years; however, recurrence after conservative breast surgery increased annually with the highest peak near five years as shown by most of the studies ${ }^{(16)}$.

So in our study obtaining clear margins was mandatory where we made certain of that by doing frozen section intraoperative. None of the patients had any malignant recurrence as confirmed by the pathologist in our multidisciplinary team. The follow up of the malignant recurrence was for the first 12-36 months as this was the time limitation of our study. Also, no cases were delayed in delivery of postoperative loco-regional irradiation or adjuvant chemotherapy, even if there was a complication of surgery.

In our study only three cases $(15 \%)$ have had complications, two cases had wound infection and dehiscence, one of them was diabetic reflecting the immune compromise with diabetes mellitus. Statistically DM has increased the risk of post-operative wound infection thrice, this similar to what was published by Urban and Rietjens $^{(\mathbf{1 7})}$ showing the complication of diabetes mellitus in oncoplastic surgery.

Those who had wound infection were admitted in hospital and treated with parenteral antibiotics and frequent daily dressing with saline and topical antibiotics. The infection was eradicated within two to three days and the patients were discharged on oral antibiotics with a more frequent follow up schedule, and when needed secondary sutures were done

We reported lower results of surgical site infection $(10 \%)$ than reported by VilarCompte et al. ${ }^{(18)}(18.9 \%)$ and higher than reported by Olsen et al. ${ }^{(19)}(4.7 \%)$.

One case of nipple necrosis with 5\%, which is conicding with results from a study conducted in 2015 for superior medial reduction mammoplasty which is depending on NAC blood supply as our study where one patient experienced unilateral necrosis of the NAC ${ }^{(20)}$.

\section{Conclusion:}

The combination of oncologic and cosmetic surgery is referred to as oncoplastic surgery. This "third pathway" allows extending the indications of BCS without compromise of oncologic goals or the aesthetic outcome. With immediate reshaping employed through OPS, major resections can now be achieved with enhanced cosmetic outcomes. 
The modification of oncoplastic surgical techniques allows combining of several benefits, as here the modified doughnut technique benefiting from combining the round block and superior medial techniques giving better access of tumors and oncological control around the breast and reduction mammoplasty in large breast of cup C, D and more, with safe NAC and good atheistic outcome.

That technique showed good adoption bilaterally which is a key for symmetrization in oncoplastic surgeries.

\section{REFERENCES}

1. Munhoz AM, Montag E and Gemperli R (2014): Current aspects of therapeutic reduction mammaplasty for immediate early breast cancer management: An update. World J Clin Oncol; 5(1): 1-18.

2. Gradinger GP (1988): Reduction mammoplasty utilizing nipple-areola transplantation. Clin Plast Surg; 15:641654.

3. Saunders C and Jassal S (2015): Breast cancer (1. Ed.). Oxford: Oxford University Press. p. Chapter 13.

4. Yang D, Lee W, Cho K, et al. (2012): Surgical techniques for personalized oncoplastic surgery in breast cancer patients with small-to moderate-sized breasts (part $1)$ : volume displacement. Journal of breast cancer; 15(1): 1-6.

5. Liang Y, Naber SP, Chatterjee A (2018): Anatomic and terminological description and processing of breast pathologic specimens from oncoplastic large volume displacement surgeries. Mod Pathol; 31(7):1004-1011.

6. Zeeneldin AA, Ramadan M, Gaber AA and Taha FM (2013): Clinico-pathological features of breast carcinoma in elderly Egyptian patients: a comparison with the non-elderly using population-based data. Journal of the Egyptian National Cancer Institute; 25(1): 5-11.
7. De La Cruz L, Blankenship SA, Chatterjee A, Geha R, Nocera N, Czerniecki BJ, Tchou J, Fisher CS (2016): Outcomes after oncoplastic breast-conserving surgery in breast cancer patients: a systematic literature review. Annals of Surgical Oncology, 2016, 23.10: 3247-3258.

8. Sanchez AM, Franceschini G, D'Archi S, De Lauretis F, Scardina L, Di Giorgio D, Accetta C, Masetti R (2019): Results obtained with level II oncoplastic surgery spanning 20 years of breast cancer treatment: Do we really need further demonstration of reliability? Breast J.

9. Munhoz AM, Montag E, Arruda EG, et al. (2006): Critical analysis of reduction mammaplasty techniques in combination with conservative breast surgery for early breast cancer treatment. Plast Reconstr Surg; 117: 1091-103.

10. Paridon MW, Sloane P, Amendoeira I, et al. (2017): Oncoplastic breast surgery: Achieving Oncological and Aesthetic Outcomes; 195-202.

11. Gardfjell A, Dahlbäck C and Åhsberg K (2019): Patient satisfaction after unilateral oncoplastic volume displacement surgery for breast cancer, evaluated with the BREAST-Q ${ }^{\mathrm{TM}}$. World J Surg Oncol; 17(1):96.

12. Erfon J, Rodrigues CMM, Markovic A (2019): Breast Reduction: 33 Years Using a Single Central Block. Aesthetic Plast Surg; 43(6): 1480-1488.

13. Aggarwal S, Marla S, Nyanhongo D, Kotecha S, Basu NN (2016): Current Practice of Therapeutic Mammaplasty: A Survey of Oncoplastic Breast Surgeons in England. Int J Surg Oncol; 2016:1947876.

14. Refaat M, Abouelnagah G, Awad AT, Fayed HM, Abdelhady DA (2019): Modified round block technique for peripherally located early cancer breast, a technique that fits for all quadrants. Breast J.

15. Blondeel P, Van Landuyt K, Monstrey S, et al. (2003): "The "Gent" consensus on perforator flap terminology: preliminary definitions." Plast Reconstr Surg, 112:13781383. 


\section{Samy A. Abdl Rhaman, et al.,}

16. Clough KB, Kaufman GJ, Nos C, Buccimazza I, Sarfati IM (2010): Improving breast cancer surgery: a classification and quadrant per quadrant atlas for oncoplastic surgery. Ann Surg Oncol; 17(5):1375-91.

17. Urban C and Rietjens M (2013): Oncoplastic and Reconstructive Breast Surgery, SpringerVerlag Italia, $1^{\text {st }}$ Edition: 13-20.

18. Vilar-Compte D, Rosales S, HernandezMello N, et al. (2009): "Surveillance, control, and prevention of surgical site infections in breast cancer surgery: a 5-year experience," American Journal of Infection Control; 37(8):674-679.
19. Olsen M, Chu-Ongsakul S, Brandt E, et al. (2008): "Hospital-associated costs due to surgical site infection after breast surgery," Archives of Surgery; 143(1):53-60

20. Jones GE, Hall-Findlay EJ. Reduction mammoplasty, Bostwick's Plastic and Reconstructive Breast Surgery, 20103 St. Louis, MO QMP (pg. 469 - 639).

$$
\begin{aligned}
& \text { تعديل لتقتية دونت لترميم الثدي كعلاج جراحى لسرطان الثدى }
\end{aligned}
$$

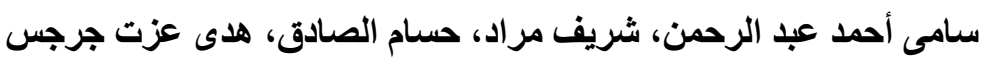

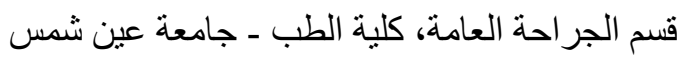

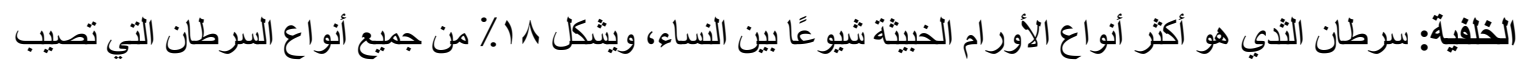

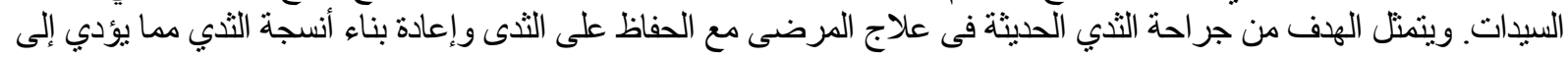
نتائج جسدية ونفية مرضية.

الهدف من الدراسة: تقيبم تعديل تقنية دونت في عملية تصغير رأب الثذي كجزء من جر احات سرطان الثدى.

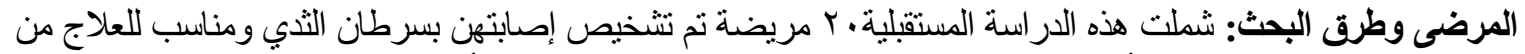
خلال استخدام تقنية دونت المعللة لرأب وتصغير الثذى وعلاج سرطان الثذى، وتنراوح أعمار هن بين بr و و • ج عامًا. وكان

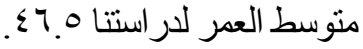

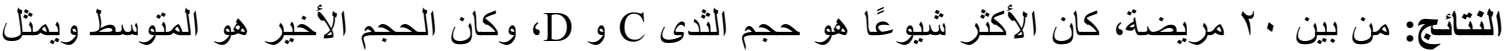

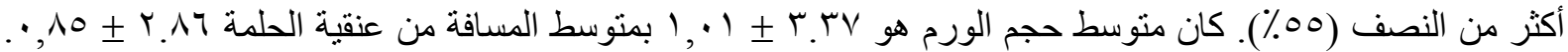

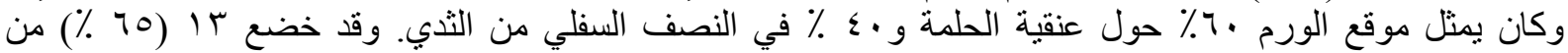

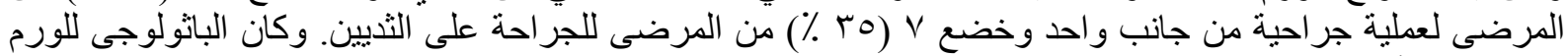

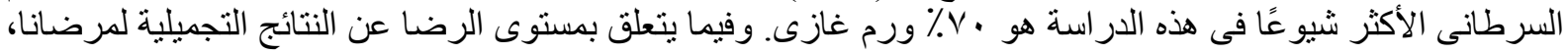

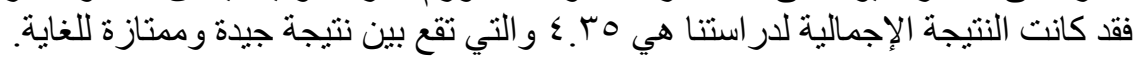

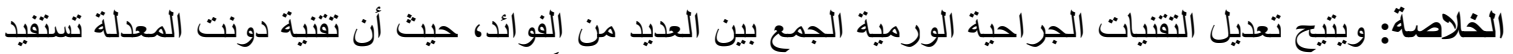

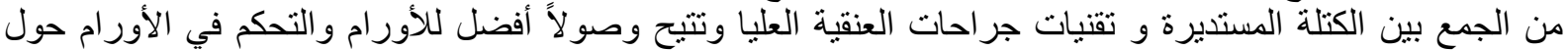

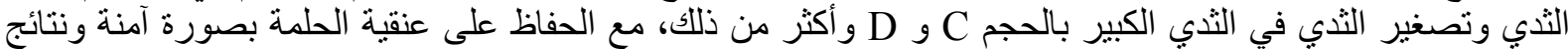
تجميلية جيدة. وقد أظهرت هذه التقنية تبنيًا جيدًا على مستوى استخدامها على كلا الثديين وهو العامل الرئيسى في في العمليات

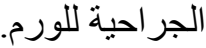

